\title{
A RELEVÂNCIA DA VIDA SOCIAL DAS FORMIGAS NA ESTRUTURAÇÃO DOS ECOSSISTEMAS TERRESTRES: CIÊNCIA E LITERATURA COMO PROPOSTA TRANSDISCIPLINAR DE CONSCIENTIZAÇÃO ECOLÓGICA
}

\author{
LA RELEVÁNCIA DE LA VIDA SOCIAL DE LAS HORMIGAS EN LA \\ ESTRUTURACIÓN DE LOS ECOSISTEMAS TERRESTRES: CIÉNCIA Y \\ LITERATURA COMO PROPUESTA TRANSDISCIPLINAR DE CONCIENCIACIÓN \\ ECOLÓGICA
}

\author{
THE RELEVANCE OF THE SOCIAL LIFE OF ANTS IN STRUCTURING \\ TERRESTRIAL ECOSYSTEMS: SCIENCE AND LITERATURE AS \\ TRANSDISCIPLINARITY PROPOSAL OF ECOLOGICAL CONSCIENTIZATION
}

Rodrigo de MELLO ${ }^{1}$

\begin{abstract}
RESUMO: A proposta do presente artigo é apresentar alguns pontos relevantes da história natural das formigas e as possíveis associações que podem ser feitas em um contexto transdisciplinar de conscientização ecológica. A partir deste grupo de insetos, é possível fazer generalizações e posteriormente estender conclusões ecológicas para outros grupos taxonômicos, estabelecendo conceitos fundamentais sobre os serviços ecossistêmicos desempenhados pelas variadas formas de vida que nos cerca - e que na maioria das vezes está oculta aos olhos humanos. Mesmo com o excepcional volume de informação disponível nos dias de hoje, principalmente por causa da revolução de meios de comunicação, a falta de integrações que esclarecem conceitos e universalidades do conhecimento ainda é um desafio contemporâneo. Ao me basear em conceitos ecológicos para apresentar a vida social das formigas, invoco passagens da literatura brasileira como proposta de uma abordagem integrativa que se manifeste em uma reflexão ecológica sobre nosso papel no gerenciamento e conservação da biodiversidade brasileira.
\end{abstract}

Palavras-chave: Formigas, ecologia, literatura, transdisciplinaridade, Cerrado.

RESUMEN: En este artículo se propone introducir algunos aspectos relevantes de la historia natural de las hormigas y los posibles vínculos que se pueden hacer en un contexto transdisciplinario de concienciación ecológica. De este grupo de insectos, es posible generalizar y luego extender conclusiones ecológicas para otros grupos taxonómicos, establecendo los conceptos básicos acerca de los servicios ecosistémicos desempeñados por las diversas formas de vida de nuestro entorno - y más a menudo se oculta al ojo humano. A pesar de la excepcional cantidad de información disponible actualmente, sobre todo debido

\footnotetext{
${ }^{1}$ Biólogo, Doutor em Ecologia e Evolução, Universidade Federal de Goiás (UFG), onde desenvolveu pesquisas no Laboratório de Genética e Biodiversidade (LGBio); Mestre em Ciências Ambientais, Universidade Estadual de Maringá (UEM); Atualmente é professor nos cursos de Biologia e Engenharia Ambiental na Universidade Católica de Brasília (UCB), Campus Taguatinga, Curso de Ciências Biológicas, Brasília, DF. E-mail: rodrigomellobr@yahoo.com.br
} 
a la revolución de los medios de comunicación, la falta de integración que aclare conceptos y universalidad del conocimiento sigue siendo un desafío contemporáneo. Basándome en conceptos ecológicos para presentar la vida social de las hormigas, invoco pasajes de la literatura brasileña como una propuesta de un enfoque integrador para manifestarse en una reflexión ecológica sobre nuestro papel en el manejo y conservación de la biodiversidad brasileña.

Palabras-clave: Hormigas, ecología, literatura, transdisciplinariedad, Cerrado.

ABSTRACT: The purpose of this paper is to present some relevant aspects of the natural history of ants, and the possible links that can be made in a transdisciplinary ecological approach. Highlighting the ecosystem services played by this group of insects, it is possible to generalize and then extend ecological conclusions to other taxonomic groups, by stablishing fundamental concepts about the ecosystem services played by the variety of life around us - that in most cases are hidden from human eyes. Despite the exceptional volume of information available today, mainly because of the media revolution, the lack of integrations that clarify concepts and universalities of knowledge is still a contemporary challenge. Based in ecological concepts to introduce the social life of antes, I invoke excerpts from Brazilian literature as a proposal to an integrative approach that triggers an eco-reflection on our role in the management and conservation of Brazilian biodiversity.

Key words: Ants, ecology, literature, transdisciplinarity, Cerrado

\section{Introdução}

Há algum tempo circularam pelas redes sociais alguns vídeos que mostravam a arquitetura de uma enorme colônia de formigas, revelando uma espantosa estrutura composta de túneis no subsolo de uma floresta ${ }^{2}$ que deixaria Oscar Niemeyer embasbacado. De imediato, lembrei-me de um provérbio sobre esses insetos que muitas pessoas pensam ser insignificantes. Salomão, o famoso rei de Israel, parece ter adquirido alguns ensinamentos pertinentes para governar seu povo depois de observar esses minúsculos artrópodes quando aconselha: "vai ter com a formiga, ó preguiçoso, e considera o seu proceder, e aprende dela a sabedoria. Não tendo ela guia, nem mestre, nem príncipe, faz o seu provimento no estio, e ajunta no tempo da ceifa com que se sustentar" (Livro dos Provérbios, 6: 6-8).

Quando norteamos abordagens ou discussões de acordo com os preceitos da Ecologia (ou de qualquer ramo científico derivado dela, como a Biologia da Conservação), temos de levar em conta toda a gama de interações que ocorre entre os seres vivos. Embora isso não seja uma tarefa nada fácil, as formigas são um bom exemplo para descortinar a complexidade de interações ecológicas que ocorrem na natureza; ainda, esse grupo taxonômico representa

\footnotetext{
${ }^{2}$ Disponível em: <http://www.youtube.com/watch?v=AlzXTnlPm48> e $<$ https://www.youtube.com/watch?v=6V2ihMtuIAY> Acessado em 15 de dezembro de 2014.
} 
bem a importância e magnitude dos serviços ecológicos prestados que são invisíveis ou negligenciados no cotidiano da maioria das pessoas. A estrutura de formigueiros mostrados em vídeos populares na web, apesar de serem impressionantes, é apenas uma pequena amostra do poder secreto destes insetos. Há muitos espaços interessantes que abordam sua vida social, desde entrevistas com especialistas ${ }^{3}$, até documentários completos ${ }^{4}$ conduzidos por entomólogos (i.e., cientistas que estudam insetos) de referência mundial no estudo desses incríveis animais, mas por ora, limito-me a invocar uma passagem que nos dá informações muito relevantes sobre o papel ecológico das formigas, ao mesmo tempo que enfatiza o nosso viés antropocêntrico de pensar o mundo. $O$ trecho a seguir é do livro autobiográfico Naturalista (1997, pg. 279) do renomado biólogo Edward O. Wilson, professor e pesquisador da Universidade de Harvard, EUA:

Manchinhas avermelhadas e escuras que ziguezagueiam pelo chão para se enfiarem buracos, elas estão em toda parte; com o peso expresso em miligramas, são habitantes de uma estranha civilização que oculta de nossos olhos sua rotina diária. Por mais de cinquenta milhões de anos e onde quer que haja terra, com exceção das camadas de gelo das regiões polares e alpinas, as formigas têm sido insetos esmagadoramente dominantes. Pelos meus cálculos, há de um a dez quatrilhões de formigas vivas, todas pesando juntas, pela ordem mais próxima de magnitude, tanto quanto a totalidade dos seres humanos.

Mas uma diferença, uma diferença vital se oculta nessa equivalência. Enquanto as formigas existem na quantidade mais correta possível em relação ao restante do mundo vivo, os humanos se tornaram numerosos demais. Se estivéssemos fadados a desaparecer hoje, o ambiente terrestre retornaria ao fértil equilíbrio que prevalecia antes da explosão populacional humana. Apenas cerca de uma dezena de espécies (entre as quais os piolhos, cães e gatos domésticos e um ácaro que vive nas glândulas sebáceas de nossa testa) dependem de nós. Mas, se as formigas desaparecessem, dezenas de milhares de outras espécies de plantas e animais pereceriam também, simplificando e enfraquecendo por quase toda parte os ecossistemas terrestres."

Este épico e retumbante sucesso na colonização e estabelecimento em solos ao redor do mundo se deve a uma exímia organização social - que chega a espantar pela simplicidade que se resume a colaboração e divisão de funções. E quando tomamos consciência deste fato, é difícil evitar a sensação de que o planeta, em boa parte, pertence às formigas, por mais desagradável que isso soe aos ouvidos humanos; é chocante perceber que as formigas não são pragas. A essência da transcrição acima é essa verdade ecológica: se as formigas

\footnotetext{
${ }^{3}$ Para uma entrevista com um especialista, acesse: http://www.observatoriodaimprensa.com.br/news/view/_ed777_mirmecologia_a_ciencia_das_formigas

${ }^{4}$ Documentário sobre a vida social das formigas, coordenado pelo entomólogo alemão Bert Hölldobler: http://topdocumentaryfilms.com/ants-natures-secret-power/
} 
desaparecessem, centenas de milhares de espécies seriam extintas e muitos ecossistemas ficariam perigosamente desestabilizados. Essa importância na estruturação dos ecossistemas terrestres do planeta se dá por regras elementares envolvidas na manutenção da vida, que essencialmente respeitam princípios básicos da termodinâmica: (1) o da conservação de energia, que prova que um sistema não pode criar ou consumir energia, mas apenas armazenála ou transferi-la, e (2) o da entropia, que é a tendência da energia se dissipar.

As formigas têm um papel fundamental no dinamismo dos ciclos biogeoquímicos que são responsáveis pelos fluxos de energia e matéria na natureza, uma vez que elas participam de muitas etapas ecológicas desses processos. Ao lado dos cupins e minhocas, as formigas arejam, revolvem e drenam diariamente toneladas de terra e assim garantem a boa saúde do solo, mais tarde enriquecido pela matéria orgânica que os insetos levam para os ninhos. "Hoje se sabe que as formigas são mais importantes que as minhocas nesse trabalho", diz o mirmecólogo (i.e., especialista em formigas), Carlos Alberto Brandão, da Universidade de São Paulo. Edward Wilson, por sua vez, calcula que elas desfazem e enterram nove de cada dez pequenos animais mortos em qualquer ponto do planeta (DIEGUEZ \& PAPAROUNIS, 1993).

A Ecologia é um ramo científico muito recente na história da ciência, o que a faz emprestar conceitos de várias áreas do conhecimento, sendo portanto uma disciplina transdisciplinar por excelência. O mais interessante na filosofia científica é justamente o fato de assumir que cientista algum poderá jamais fazer uma descoberta sem se basear sobre os elementos deixados por seus antecessores. E tão espantosa quando interessante, é a constatação que certas ideias são compartilhadas em várias linhas de pesquisa. É atribuído a Antoine Laurent de Lavoisier (1743 - 1794), o químico francês considerado o pai da química moderna, um aforismo bem conhecido que encerra em si a ideia mais elementar da termodinâmica e da própria ecologia: "Na natureza nada se perde, nada se cria, tudo se transforma".

Os ecossistemas terrestres não fogem à essa regra, afinal eles funcionam como qualquer sistema termodinâmico estudado por físicos ou químicos que investigam o comportamento de partículas, átomos ou moléculas. Na ecologia, entretanto, a unidade mais básica e fundamental para o entendimento de um ecossistema é a espécie, daí a importância de se conhecer bem a história natural de nossa flora e fauna para entendermos a dinâmica e funcionamento de comunidades e ecossistemas. Somente assim poderemos nos beneficiar de 
seus serviços, inclusive para nosso bem-estar e qualidade de vida, sem a agressão desenfreada e inconsequente da atualidade, e para isso é essencial que continuemos a aprender e encontrar soluções observando o mundo vivo ao nosso redor - mas nos inserindo no ambiente como mais um ramo na árvore da vida, e não com o pensamento antropocêntrico de estamos no topo de alguma escala evolutiva.

\section{A natureza é grande nas coisas grandes, e grandíssimas nas pequeninas: o valor das pequenas coisas na Ecologia e na Evolução}

O sucesso evolutivo das formigas tem muito a ver com a vida em grupo, uma preciosa combinação envolvendo organização, especialização e cooperação, tudo isso sustentado por um sistema de comunicação, sobretudo química, desenvolvimento durante sua longa história evolutiva (WILSON, 2013). A seleção de hábitat, por exemplo, é feita por uma espécie de consenso. Cada formiga libera marcadores químicos em partes da trilha, informando assim que tem preferência por aquele trecho. Comunicação, colaboração: quanto mais forte o sinal químico, mais a trilha é usada. Portanto, elas não têm líder, e sim um consenso da comunidade, que é estabelecido pela intensidade do 'aroma químico'. Outro exemplo de cooperação é o que os cientistas chamam de 'estômago social': em algumas espécies, castas especializadas regurgitam o alimento coletado fora do formigueiro para os indivíduos que ficaram trabalhando na manutenção interna da colônia. Cada vez mais, as pesquisas com esses insetos mostram a grandiosidade da ação em conjunto, que equivale a um superorganismo. Para se ter uma ideia da magnitude do impacto ecológico desses insetos, basta dizer que o consumo de biomassa pelas formigas dos pampas argentinos afeta o consumo de capins por parte do gado criado na região.

Se a sociedade humana ainda tem muito o que aprender com as das formigas, somos dignos de dó quando nos compararmos individualmente com esses guerreiros em miniatura. Além de já nascerem com uma estrutura corporal (exoesqueleto) que mais parece uma armadura de samurai, experimentos mostram que a taxa metabólica das formigas é bem superior à nossa - e.g., ao cortar uma folha com suas mandíbulas, a taxa metabólica de uma formiga é três vezes maior do que a de um atleta no máximo de sua performance. Sem contar a carga transportada em proporção ao peso corporal ou às distâncias percorridas. Nesse sentido, uma saúva carregando apressadamente um pedaço de folha equivaleria a um ser 
humano carregando um fardo bem pesado, por dezenas de quilômetros, sem parar, a uma velocidade que nunca atingiríamos a pé.

Oliveira (1990) faz um levantamento de curiosidades interessantes relacionadas a refinada organização social das formigas, e como elas não cessam de maravilhas os pesquisadores. Para o nosso contexto, vale ressaltar que se todos os animais terrestres fossem colocados numa balança, 1/10 do peso (cerca de 900.000 toneladas) seria representado por formigas, esse inseto com menos de um milionésimo da massa de um ser humano. Isso significa que a população de formigas é maior que a de todas as aves, répteis e anfíbios juntos, sendo estimada em torno de 10 quintilhões de indivíduos (o número 1 seguido de dezenove zeros). "Mas não é pelo peso ou pelo número que as formigas devem ser distinguidas", lembra o entomolólogo americano E. O. Wilson, da Universidade Harvard. "O desaparecimento desses insetos poderia levar à extinção milhares de espécies, desestabilizando a maioria dos ecossistemas." Wilson e seu colega Bert Hölldobler publicaram em 1994, nos Estados Unidos, o livro Ants (Formigas), logo aclamado como um clássico, onde analisam o comportamento de seus animais preferidos e aponta várias peculiaridades de sua organização social.

Outro papel ecológico desempenhado pelas formigas que é de suma importância é a disseminação de sementes de plantas e a função de 'faxineiras', já que comem até $90 \%$ dos cadáveres de pequenos animais. Todos esses trabalhos são levados muito a sério. Para começar, nada de sexo - atividade exclusiva das rainhas. As trabalhadoras devem se limitar a fazer a parte que lhes toca para conservar o lar comunitário e garantir a propagação dos genes de sua parenta privilegiada. Assim, para realizar suas funções com plena eficiência, cada uma se especializa ao máximo, mudando a própria anatomia. Os soldados são fêmeas que trocaram os órgãos reprodutores por um abdômen cheio de armas biológicas. O gênero asiático Camponotus, por exemplo, é uma verdadeira bomba, que rompe o próprio corpo para lançar veneno sobre os adversários. As lava-pés, como são conhecidas as Solenopsis invicta nativas do sul do Brasil, tem um veneno forte que causa sensação de queimadura. Elas associam-se em colônias protegidas por um contingente de até 100.000 soldados. Longe de casa, são capazes de unir-se rapidamente para o combate por meio de ordens químicas. As formigas, por sinal, dominam uma linguagem química complexa. Uma colônia comum pode farejar no ar 1 trilionésimo de grama de uma dúzia de sinais de cheiros diferentes, de acordo com os feromônios secretados no solo por várias glândulas. É desse modo que uma operária indica a outra companheira o caminho até um inseto morto. Mas o talento das formigas como 
químicas tem seu melhor exemplo na Oecophylla, a formiga-tecelã que vive em árvores. Presentes em abundância nas florestas da África e no sudoeste da Ásia, elas se utilizam da seda produzida pelas larvas para ligar folhas e galhos, formando grandes e seguros pavilhões aéreos, que funcionam como as teias das aranhas (OLIVEIRA, 1990).

Atualmente é bem sabido pela ciência que o $\mathrm{CO}_{2}$ é o principal gás emitido por meio de atividades humanas, de acordo com a Revisão de Gases Estufa da Agência de Proteção Ambiental dos Estados Unidos. E o volume liberado só aumentou desde a revolução industrial, contribuindo para o aquecimento global. O que foi novidade para a comunidade científica muito recentemente é que as formigas também podem ajudar a capturar $\mathrm{CO}_{2} \mathrm{e}$ auxiliar na luta contra o aquecimento global. Schults (2014) explica os detalhes mais relevantes de estudo publicado recentemente no periódico Geology, onde os pesquisadores associaram as formigas à aceleração do armazenamento de dióxido de carbono natural em rochas. Respondendo ao estudo, David Schwartzman, professor emérito de biogeoquímica da Howard University que revisou a pesquisa, declarou que as formigas podem ter um papel importante parar o sequestro de carbono da atmosfera, embora as pesquisas nessa área ainda estão apenas em seus primeiros passos.

Por outro lado, o papel das formigas na cadeia alimentar já é bem conhecido pelos ecólogos. Muitas aves, lagartos, sapos, alguns besouros e também o homem incluem esses insetos em suas dietas. "Os índios tupis já preparavam há centenas de anos as ycobas (içás), palavra que significa gordura, devido ao abdômen cheio de ovos", informa o zoólogo Nélson Papavero, no livro Insetos no folclore. "Eram torradas como amendoim, moqueadas e servidas com molho de tucupi bem apimentado ou então assadas em paçoca com farinha de mandioca", descreve Papavero. Alguns grupos indígenas usam também as gigantes saúvassoldados como grampos para ligar as bordas de cortes na pele. A aplicação é simples: colocam as formigas para morder a ferida e arrancam seus corpos, ficando a cabeça presa ao ferimento para auxiliar a cicatrização (OLIVEIRA, 1990).

\section{A organização e eficiência da vida em sociedade: as saúvas como personagens da} história do Brasil

Qualquer pessoa que tenha observado as paisagens em torno das estradas ou reparado em algum pasto em sua cidade já avistou grandes formigueiros ou cupinzeiros, uma vez que ao edificar suas moradas estes insetos acumulam montes de terra na superfície, chegando a 
alturas consideráveis. Oliveira (1990) ressalta que essas construções de terra são endurecidas como um verdadeiro telhado de barro, que acabam abrigando alguns atraindo outros, como tatus e tamanduás, cujo prato predileto (e invariável o ano inteiro) são precisamente formigas saúvas. Outros bichos preferem esperar a época da primavera, quando as formigas aladas encarregadas da reprodução (no caso das saúvas, elas conhecidas como içás ou tanajuras, no caso das fêmeas, e bitus, os machos) começam a revoada de acasalamento. $\mathrm{O}$ autor também discute os benefícios e prejuízos que as formigas podem causam aos seres humanos, pois com a mesma eficiência que elas revolvem a terra e contribuem para a fertilidade do solo, elas também pode destruir lavouras inteiras ou mesmo competir com o gado por gramíneas.

Essa voracidade das saúvas fez com que elas adquirissem má fama, pois são uma das forças mais dominantes do planeta, e em alguns casos, tão inteligentes quanto suas primas, as abelhas. Dieguez. \& Paparounis (1993) destacam que os entomólogos defendem que as formigas possuem uma espécie de inteligência que não funciona no cérebro, mas sim embutida nas habilidades desenvolvidas em conjunto por esses pequenos seres. Acima de tudo, sua sagacidade transparece por meio da vida em sociedade: entre milhões de espécies classificadas na categoria dos insetos, apenas as formigas e os cupins desenvolveram ao máximo esse método de dividir tarefas e multiplicar a eficiência do trabalho. Em suas comunidades, todas as fêmeas operárias são estéreis e os machos servem apenas para inseminar a rainha, única fêmea fértil. Chamam-se "eussociais" os seres que praticam tal forma de matriarcado, que foi decisiva: somente $5 \%$ de todas as espécies de abelhas, por exemplo, têm comportamento social, mas estas últimas superam largamente em número os $95 \%$ restantes.

Não é à toa, portanto, que costuma-se dizer que colmeias e formigueiros não são simples ninhos, e sim uma espécie de 'superorganismo'. As bem conhecidas colmeias abrigam em média 50.000 moradores, mas os sauveiros são ainda mais complicados, e podem reunir mais de 5 milhões de habitantes. Em cada um deles, túneis estreitos interligam dezenas de câmaras - os locais onde as saúvas efetivamente vivem. São ocos subterrâneos, geralmente com meio metro de altura, usados para diversas funções: desde lixeiras comunitárias (também usadas como cemitérios), até berçários onde a rainha deposita ovos. No final, a construção equivale a um prédio de três andares enterrado a 10 metros de profundidade. Aí, o maior compartimento é o de cultivo, onde folhas que chegam do exterior são dispostas com cuidado e adubadas com o hormônio fertilizante, excretado pela rainha, o ácido indolil-acético. Uma casta inteira de saúvas, as chamadas jardineiras, com cerca de 2 
milímetros de comprimento, nunca sai do formigueiro. Elas existem para cuidar do fungo, o que inclui cortar 'ervas daninhas', ou seja, os fungos que não servem para comer. As cortadeiras, que trazem as folhas, têm 5 milímetros e labutam no mundo externo sob a proteção dos taludos soldados, com 1,5 centímetro. Estima-se que um sauveiro maduro chega a cortar cerca de 8 toneladas de folhas por ano - o suficiente para alimentar três bois. (DIEGUEZ. \& PAPAROUNIS, 1993).

Sem dúvida, foi justamente essa eficiência que sustentou o visceral preconceito contra a saúva, sendo possível identifica-las até em passagem literárias, o que reflete que as saúvas estão relacionadas com a própria história do Brasil. Já em 1560, o padre José de Anchieta afirmava desdenhosamente que, entre as formigas do país, só mereciam menção "as chamadas içás, que estragam as árvores”. O personagem Macunaíma, da obra homônima, de 1928, do escritor modernista brasileiro Mário de Andrade, também faz menção a essas formigas em particular quando atesta que "pouca saúde e muita saúva, os males do Brasil são". Esse verso parece inspirado num vaticínio famoso, escrito 100 anos antes pelo naturalista francês Auguste Saint-Hilaire: “Ou o Brasil acaba com a saúva ou a saúva acaba com o Brasil”. No entanto, o erro básico desse modo de ver as formigas como inimigas é tirar da trama o principal vilão da história: o próprio homem. Hoje sabemos, por exemplo, que uma das causas da proliferação de saúvas que acabou por provocar prejuízos catastróficos na economia brasileira no século passado se deve as drásticas reduções populacionais de tamanduás e outros vertebrados que incluem as saúvas em sua dieta, uma vez que sofreram com a fragmentação de hábitat provocado pelo avanço agrícola da época para cultivo das plantações de café, uma das principais engrenagens econômicas do país naquela época.

É fácil perceber, à luz da ecologia, que a saúva causa grandes estragos onde o homem gerou fortes desequilíbrios ecológicos. Os pastos são um exemplo histórico: em alguns deles se podem contar até mais de 50 sauveiros em cada quadrado de apenas 100 metros de lado. Um caso notório dessa prática ocorreu em Mato Grosso do Sul, que se diz ostentar a maior concentração de formigueiros do mundo: reunidos num só, eles cobririam 500 quilômetros quadrados, área quase igual à da cidade de Porto Alegre. O desastre foi detectado no centro do Estado, onde a mata de 2.500 quilômetros quadrados havia sido derrubada para dar lugar monocultura de eucaliptos. A conclusão inevitável dos biólogos é que a 'praga' saúva segue os desajeitados passos humanos na natureza. E não só a saúva: a doméstica lava-pés, por exemplo, tem sido acusada de devorar até crianças no Estado americano do Texas, para onde 
foi levada provavelmente em cargas de navios (OLIVEIRA, 1990; DIEGUEZ \& PAPAROUNIS, 1993).

No caso das saúvas brasileiras, apesar de preferirem fazer o corte de folhas à noite para evitar os predadores, é possível vê-las trabalhando durante o dia caso pressintam, por mecanismos ainda desconhecidos, a chegada de chuvas no entardecer. Oliveira (1990) destaca que durante as tempestades, estas incansáveis formigas finalmente param de trabalhar para se proteger no interior dos ninhos que, embora feitos de terra, não ficam completamente inundados. As câmaras internas, ou panelas, como se denominam os grandes salões no interior do sauveiro, são dispostas lateralmente aos túneis de forma a evitar que sejam destruídos pelas grandes chuvas. Como nos diversos ambientes de uma residência humana, em cada câmara pratica-se um tipo de atividade diferente. No que se poderia chamar de cozinha, ou horta comunitária, cultiva-se um fungo para a alimentação de toda a colônia; nos quartos funcionam um tipo de berçário para os ovos das saúvas, também criados em meio ao fungo, e em outras dependências funcionam o 'lixão' e o cemitério, onde são depositadas as formigas mortas da colônia. O fungo que serve de alimento às formigas, o Pholota gongylophora, por sinal, só pode ser encontrado em câmaras específicas. Ali, operárias jardineiras, medindo de 2 a 3 milímetros, picam em partes cada vez menores os pedaços de folhas que chegam, as quais são implantadas nas esponjas de fungos, que as utilizam como alimento. Além disso, as jardineiras retiram constantemente pedaços mortos do fungo, assim como folhas secas, e mantêm as condições climáticas ideais para o desenvolvimento do fungo, já que longe desses cuidados, o Pholiota raramente sobrevive. Mas todo esse esforço despendido pelas formigas é compensado, uma vez que tal fungo lhes fornece a capacidade de digerir a celulose e outras substâncias tóxicas dos vegetais.

Numa coisa, portanto, o herói de Mário de Andrade estava certo: as diversas espécies do gênero Atta são o maior grupo de formigas do Brasil. O padre Anchieta e Saint-Hilaire também anunciam bem o poder de um dos exércitos mais poderosos do mundo que, embora compostos por minúsculos invertebrados, são capazes de arquitetar câmaras, galerias e túneis faraônicos e muito bem organizados para o funcionamento pleno do formigueiro. Mais uma vez, devido a constante combinação que esses insetos sociais desenvolvem com maestria: organização, especialização e cooperação. 


\section{Fluxo de energia e o conceito de capacidade de suporte: o que é ser 'ecologicamente correto'? Uma lição a ser aprendida pelos humanos}

Em última instância, toda e qualquer espécie tem o crescimento de suas populações limitado pela disponibilidade de recursos no seu ambiente. Foi dessa fonte que bebeu o próprio Charles Darwin (1809-1882) durante a gestação de sua teoria evolutiva, pois foi após ler o livro "Ensaio sobre princípios populacionais", do economista Thomas Malthus (17661834), é que o jovem naturalista inglês foi capaz de conceber o raciocínio de seleção natural o mecanismo que favorece os organismos mais bem adaptados para competir por recursos do ambiente. Se somos mais uma espécie animal, nós não temos como fugir dessa regra; pesquisas comportamentais com colônias de formigas podem oferecer informações preciosas sobre o fluxo de energia e capacidade de suporte, algumas das quais podem ser aplicadas ao Homo sapiens.

Em um estudo hoje considerado clássico, Lugo e colaboradores (1973) investigaram as saúvas (Atta colombica) que vivem nas florestas tropicais úmidas da Costa Rica, onde coletam fragmentos de folhas novas na vegetação, levando-os aos formigueiros subterrâneos a fim de servirem de substrato para culturas de fungos, dos quais elas se alimentam. Os pesquisadores estimaram os gastos de energia das diferentes atividades dentro de uma colônia e concluíram que a capacidade de suporte (i.e., o tamanho máximo da colônia) é atingida quando a entrada de calorias, na forma de folhas coletadas, equilibra o custo energético do trabalho envolvido no corte e transporte das folhas, na manutenção das trilhas e no cultivo dos fungos. Os pesquisadores observaram ainda que, em um dado momento, nas colônias grandes, $25 \%$ das formigas estavam carregando folhas, enquanto $75 \%$ estavam cuidando das trilhas e dos jardins de fungos. Quando a entrada de energia era equilibrada pelos custos de manutenção, a colônia parava de crescer.

Graças a estudos como esses, sabemos hoje que as colônias de formigas dependem de subsídios enormes importados de fora, tirados, muitas vezes, de fontes que se acumularam muito antes do aparecimento do ser humano. É consenso entre os pesquisadores que as populações humanas parecem se aproximar dos níveis máximos da capacidade de suporte dos seus respectivos ambientes. Apesar de atualmente a taxa de crescimento da população humana ser declinante, parar de crescer não impedirá que o consumo global deixe de aumentar. A chave do problema é baixar a taxa de consumo per capita, já que os recursos limitantes que 
mais causam preocupação atualmente são alimento, hábitat e combustíveis fósseis (ODUM \& BARRET, 2007).

A explosão demográfica humana das últimas décadas foi promovida pelo aumento da quantidade de alimento disponível e, mais recentemente, pelas melhorias no saneamento básico. O primeiro fator elevou a taxa de natalidade, enquanto o segundo reduziu a de mortalidade. Um exemplo familiar é o hino da copa do mundo de futebol de 1970, que dizia “noventa milhões em ação, pra frente Brasil do meu coração...”. E fomos! Segundo o Instituto Brasileiro de Geografia e Estatística, o Brasil comportava mais de 190 milhões de habitantes em 2010. Em 40 anos, portanto, mais do que dobramos a nossa população. Uma consequência lógica disso foi o aumento na demanda por bens e serviços, o que implicou em derrubarmos (mais) florestas, construirmos (mais) barragens - o que resultou em alagarmos (mais) terrenos - e, por fim, produzirmos (mais) lixo e contaminantes. No fim das contas, a demanda por mais espaço tende a fazer com que outras espécies percam seus hábitats, seja para a construção de casas, ruas, rodovias, pastos ou plantações.

Como levantado anteriormente, não fomos os inventores da agricultura e da pecuária, e sim as formigas. Apenas dois gêneros de todo o reino animal foram espertos o bastante para fugir às incertezas da vida e garantir a sobrevivência por meio daquilo que semeiam e colhem. O homem é definitivamente um novato: existe há pouco mais de 2 milhões de anos, aprendeu a arte do cultivo há coisa de 100 séculos e hoje é representado por uma única espécie sobre a face do planeta, o Homo sapiens. Embora o processo de domesticação foi, sem dúvida, um dos eventos mais importantes da história humana, ela é muito recente em nossa história evolutiva. A nossa agricultura, segundo os arqueólogos, parece ter surgido e se espalhado em diferentes regiões do mundo, em algum momento entre 10.000 e 5.000 anos atrás. A transição de uma vida como coletores-caçadores para uma vida como cultivadores de alimento fez com que a nossa civilização se tornasse sedentária e prosperasse, o que na literatura técnica passou a ser chamado de 'a revolução do Neolítico' (WEISDORF, 2005). Por outro lado, as formigas veem fazendo esses cultivos de outros seres vivos há milhões de anos.

Os pulgões, que são parentes próximos das cigarras e dos percevejos, têm uma relação mutualística histórica com as formigas que antecede qualquer hominídeo que já tenha passado pela face da Terra. Os pulgões se alimentam de seiva das plantas, um material rico em açúcares, e o que não é digerido é avidamente consumido por certas formigas. Estas, por sua vez, cuidam do 'rebanho de pulgões' ao afugentar predadores (GULLAN \& CRANSTON, 
2013). Além da domesticação de animais, algumas formigas são ótimas agricultoras, já que cultivam fungos no interior de seus formigueiros. Cada pedaço de folha que chega a uma colônia é tratado com um defensivo natural produzido pelas próprias formigas, para evitar que microrganismos proliferem e contaminem o jardim de fungos. A eficiência desse processo é muito superior ao que acontece quando aplicamos pesticidas para combater as pragas de nossas lavouras.

Nossas formidáveis concorrentes, que existem há um tempo que se mede na casa dos 100 milhões de anos, trazem do berço as técnicas agrícolas e são representadas por dezenas de espécies sobre a Terra. São as saúvas que aprenderam a cultivar um fungo sobre um canteiro de folhas cortadas, para depois usá-lo como alimento. Por isso, muitos entomólogos, estudiosos de insetos, as consideram os mais avançados animais dessa categoria - talvez mais que as abelhas, suas primas. Não é à toa que saúvas e abelhas têm tanta importância no mundo moderno. Ambas são descendentes de um inseto sagaz que há mais de 200 milhões de anos descobriu um meio de colonizar o subsolo, que era, então, um vasto e inexplorado ambiente, apenas à espera de um aventureiro que o ocupasse (DIEGUEZ \& PAPAROUNIS, 1993). Manter uma dieta bem versátil também ajuda: "elas podem explorar diferentes recursos de um ambiente sem limitação por especialização alimentar", diz o biólogo Rodrigo Feitosa, da USP. Isso significa que as formigas não são superespecialistas em sua dieta; se uma fonte de alimento acaba, elas se organizam para procurar outra sem deixar o formigueiro desprotegido (COHEN, 2013).

Em organismos eussociais, como formigas, são as características da colônia que são transmitidas às futuras gerações. Ou seja, o conceito de evolução se aplica ao coletivo, não ao indivíduo. As formigas que não se reproduzem, como as operárias, têm mais tempo para se especializar em outras tarefas, como a busca de alimento e a defesa do ninho. Cohen (2013) afirma que para os biólogos essa capacidade de evoluir em grupo é um dos fatores que garantiram a sobrevivência das formigas por mais de 100 milhões de anos, lembrando que as formigas têm relações simbióticas (com vantagens para todos) com mais de 400 espécies de plantas, milhares de artrópodes, fungos e micro-organismos. 


\section{Formigas e literatura: como pôr em prática abordagens conservacionistas e transdisciplinares? Um exemplo com Guimarães Rosa e os sistemas ecológicos do Cerrado}

Mesmo com o excepcional volume de informações disponíveis nos dias atuais, principalmente por causa das facilidades trazidas pela revolução dos meios de comunicação, a falta de integrações que esclareçam conceitos e universalidades do conhecimento ainda é um desafio. É urgente e crescente a necessidade de se promover uma alfabetização ambiental científica e séria da população, mas essa abordagem de níveis múltiplos e escala ampla envolve sistemas inteiros de educação e inovação. Essa proposta de abordagem integrativa, que se preocupa em desvendar explicações de causa e efeito por meio de um entendimento transdisciplinar, tem sido chamada na literatura científica de consiliência (WILSON, 1999), de ciência da sustentabilidade (KATES et al., 2001) e de ciência integrativa (BARRET, 2001).

De fato, o desenvolvimento continuado da Ecologia parece estar cada vez mais se estabelecendo como ciência integrativa, tão necessária aos dias de hoje. No entanto, estratégias transdisciplinares ainda são muito pouco exploradas no dia-a-dia das escolas brasileiras, mesmo já sendo bem sabido que para se divulgar ciência de maneira clara e efetiva, o público deve se sentir inserido no processo histórico, reencontrando-se nos outros e identificando-se com eles. Somente esta conscientização é capaz de fazer com que o conhecimento seja uma construção social que possa fazer o estudante transitar da inércia para a autonomia, com participação ativa no meio em que vive, e não um mero produto final resultante do acúmulo de dados e informações (FREIRE, 1987; TORRES, 1997).

O escritor Guimarães Rosa, cuja biografia mostra que ele viajou com tropeiros antes de compor suas obras, é citado aqui como exemplo por estar inserir as realidades locais do Brasil, fornecendo uma caracterização detalhada do sertanejo (seus costumes, vocabulário, crenças), e também eternizando ambientes naturais pela descrição dos cenários de suas histórias de modo bastante convincente. Em grande parte de seus livros ou contos, o escritor mineiro compõe paisagens e dinâmicas do Cerrado de uma maneira tão acurada que talvez apenas biólogos muito experientes soubessem descrever. Um professor não teria grandes dificuldades em explorar os conceitos ecológicos e os aspectos comportamentais da flora e da fauna desse bioma, implícitos nos trechos a seguir: 
Do povinho mais miúdo, por enquanto, apenas o eterno cortejo das saúvas, que vão sob as folhas secas, levando bandeiras de pedacinhos de folhas verdes, e já resolveram todos os problemas do trânsito. Ligeira, escoteira, zanza também, de vez em quando, uma dessas formigas pretas caçadoras amarimbondadas, que dão ferroadas de doer três gritos. Mas aqui está outra, pior do que a preta corredora: esta formiga-onça rajada, que vem subindo pela minha polaina. Está com fome. Quer das provisões. Desço-a e ponho-lhe diante de um grumo de geleia e alguns grãos de farinha. Não quis. Fugiu. Quem vai comer do meu farnel é todo o clã das quem-quem, esses trenzinhos serelepes, que têm ali perto a boca do seu formigueiro. Uma por uma, se entrevem; largam os glóbulos de terra, trocam sinais de antenas, circulam adoidadas e voltam para a cratera vermelha. Vou espalhar no chão mais comida, pois elas são sempre simpáticas: ora um menino que brinca, ora uma velhinha a rezar.

Como será o deus das formigas? Suponho-o terrível. Terrível como os que o louvam... E isto é também como o louva-a-deus, que, acolá, ereto, faz vergar a folha do junquilho. Ele está sempre rezando, rezando de mãos postas, com punhais cruzados. Mas, no domingo passado, este mesmo, ou um qualquer louva-a-deus outro, comeu o companheiro em oito minutos, medidos no relógio - deixou de lado apenas as rijas pernas-de-pau serrilhadas da vítima, e o seu respectivo colete....Foi-se. (...). Então fiquei meio deitado, de lado. Passou ainda uma borboleta de páginas ilustradas, oscilando no voo pulandinho e entrecortado das borboletas; mas se sumiu, logo, na orla das tarumãs. Então, eu só podia ver o chão, os tufos de grama e o sem-sol dos galhos. Mas a brisa arageava, movendo mesmo aqui em baixo as carapinhas dos capins e as mãos de sombra. E o mulungu rei derribava flores suas na relva, como se atiram fichas ao feltro numa mesa de jogo. Paz.

- trecho do conto São Marcos, na obra Sagarana (ROSA, 2001, pg. 282).

E ele achava muitas coisas bonitas, e tudo era mesmo bonito, como são todas as coisas nos caminhos do sertão. (...) Pela primeira vez na sua vida, se extasiou com as pinturas do poente, com os três coqueiros subindo da linha da montanha para se recortarem num fundo alaranjado, onde, na descida do sol, muitas nuvens pegam fogo. E viu voar, do mulungu, vermelho, um tié-piranga, ainda mais vermelho - e o tié-piranga pousou num ramo de barbatimão sem flores, e Nhô Augusto sentiu que o barbatimão todo se alegrava, porque tinha agora um ramo que era de mulungu.

- trecho do conto A hora e a vez de Augusto Matraga, na obra Sagarana (ROSA, 2001, pg. 401-402)

O chapadão é sozinho - a largueza. O sol. O céu de não se querer ver. O verde carteado do grameal. As duas areias. As arvorezinhas ruim-inhas. A diversos que passavam abandoados de arraras - araral - conversantes. Aviavam vir os periquitos, com o canto-clim. Ali chovia? Chove - e não encharca poça, não rola enxurrada, não produz lama: a chuva inteira se sorve em minuto terra a fundo, feito um azeitezinho entrador. $O$ chão endurecia, cedo, esse rareamento de águas. $\mathrm{O}$ fevereiro feito. Chapadão, chapadão, chapadão. De dia, é um horror 
de quente, mas pra noitinha refresca, e de madrugada se escorropicha de frio, o senhor isto sabe.

- trecho do romance Grande Sertão: Veredas (ROSA, 2001, p. 339-40).

Destrinchar os processos ecológicos, evolutivos e biogeográficos subjacentes nestas curtas passagens pode, concomitantemente, despertar o interesse de alunos que tenham inclinação para as Letras. O modo peculiar de escrever de Guimarães Rosa pode estimulá-los a se iniciar e/ou se aventurar, também, no mundo da literatura. É, pois, sob essa abordagem que o conhecimento científico também pode ser trabalhado: integrando-o a outros campos do saber. A ideia é justamente descortinar para os educandos a conectividade que existe entre as universalidades do conhecimento, sejam elas artísticas, culturais, históricas, sociais, religiosas ou científicas

\section{O homem como gerenciador de biodiversidade: reflexões para o Brasil}

O Brasil é conhecido por sua extraordinária diversidade de espécies de formigas e há muitas décadas nossos cientistas estão dedicados a estudar vários aspectos do grupo, desde sistemática, história natural, comportamento, ecologia, interações com plantas, até fatores que influenciam o número e a composição de espécies de comunidades de formigas nos diferentes ecossistemas brasileiros. Este grupo taxonômico, portanto, é um exemplo para se demonstrar toda a complexidade das interações ecológicas que ocorrem na natureza.

Em geral, as pessoas costumavam manter uma relação de grande intimidade com os locais em que viviam. Nossos antepassados eram caçadores-coletores, pequenos lavradores ou pastores, pessoas que tinham de saber com exatidão todos os detalhes físicos da região de onde tiravam o sustento, caso quisessem manter intacto seu modo de vida. A maioria de nós, que vive no mundo moderno, nada tem de comparável a isso, exceto conhecimento prático e infraestrutura de nossa própria civilização extremamente técnica. No entanto, ver e apreciar, participar o tempo todo e desde sempre de padrões que não foram estabelecidos por nós. Lopes (2007), destaca que algum dia alguém ainda irá explicar as raízes da solidão humana moderna por essa perda de intimidade com o meio ambiente, pelas nossas incontáveis transgressões em relação ao planeta físico. $\mathrm{O}$ autor enfatiza que já não temos mais nenhum relacionamento com a Terra, e mesmo quando ele existe, quase sempre é rápido demais, insuficiente para que as coisas sejam absorvidas. Nessa linha de raciocínio, as formigas demostram ser um bom grupo taxonômico para se ter uma ideia da complexidade e importância das relações ecológicas que ocorrem no meio ambiente que o homem compartilha com outros milhares de seres vivos. 
Wilson (2008) afirma que nossa relação com a natureza é primal e discute que as emoções que ela desperta devem ter surgido durante a esquecida pré-história da humanidade e, portanto, são profundas e obscuras. A atração gravitacional da natureza sobre a psique humana pode ser expressa em um único termo, mais contemporâneo: biofilia, definido como a tendência inata para se afiliar à vida e aos processos vitais. O pesquisador ressalta que, desde a infância até a velhice, as pessoas de todas as partes do mundo sentem atração pelas outras espécies, mostrando que a apreciação da diversidade da vida é universal e intrínseca ao ser humano. Explorar a vida e filiar-se a ela, transformar criaturas vivas em metáforas carregadas de emoção, inseri-las na mitologia e na religião - eis os processos fundamentais, facilmente reconhecíveis, da evolução cultural biofílica. Essa filiação tem uma consequência moral: quanto mais compreendemos outras formas de vida, mais o nosso aprendizado se expande, abrangendo a sua vasta diversidade, e maior é o valor que atribuímos a elas - e, evidentemente, a nós mesmos. Wilson (2008, p. 78-79) discute como essa filiação influencia as nossas preferências por certos habitats:

“...os pesquisadores já descobriram que quando pessoas de diversas culturas, incluindo as da América do Norte, da Europa, da Ásia e da África, têm liberdade de escolher seu local de residência e trabalho, elas preferem um ambiente que combine três características. Desejam morar em um lugar alto, com vista para fora e para baixo; de onde se possa ver uma área verde, com árvores esparsas e pequenos bosques, mais semelhante a uma savana do que a um campo relvado ou a uma floresta densa; e que esteja perto de uma fonte de água, tal como um lago, um rio ou o mar. Mesmo que todos esses elementos sejam puramente estéticos e não funcionais, como acontece nas residências de veraneio, aqueles que dispõem de meios para tanto estão dispostos a pagar preços elevados para obtê-los. Em testes com várias opções, verificou-se que as pessoas preferem que sua moradia seja um retiro, com uma parede, rochedo ou alguma outra coisa sólida na parte de trás. Elas desejam ver um terreno frutífero em frente ao seu retiro. Apreciam que animais grandes, silvestres ou domésticos, estejam espalhados pelo local.

(...) Embasada em consideráveis evidências do registro fóssil, essa interpretação sustenta que os seres humanos de hoje continuam escolhendo habitats semelhantes àqueles em que a nossa espécie evoluiu, na África, durante milhões de anos de pré-história. Nossos distantes antepassados desejavam ficar ocultos em pequenos bosques com vista para uma savana ou em áreas de presas para perseguir, animais abatidos para recolher e deles alimentar-se, plantas comestíveis para coletar, inimigos para evitar. Um curso d'água nas proximidades fazia as vezes de limite territorial e fonte de alimentos.

Será tão estranho que pelo menos um resíduo dessa escolha de hábitat persista entre os instintos humanos? A busca programada pelo ambiente correto é um comportamento universal das espécies animais, pela melhor das razões - trata-se de um imperativo para a sobrevivência e a reprodução.

Embora essas várias linhas de evidências sejam apenas fragmentárias, elas nos dizem que grande parte da natureza humana foi programada geneticamente durante os longos períodos em que nossa espécie viveu em contato íntimo com o resto do mundo natural vivo. Hoje as 
pessoas da maioria dos países não dão mais importância a essa conexão. Elas expulsaram a natureza viva para as margens da existência, e o declínio desta tem uma prioridade baixíssima na ordem das suas preocupações. Com o aumento dos conhecimentos científicos sobre a natureza humana e a natureza viva, essas duas forças criativas da auto-imagem humana irão unir-se. A ética central vai mudar, e fecharemos o círculo, passando a apreciar e valorizar todas as formas de vida - e não apenas a nossa.

Os biomas brasileiros, assim como os do resto do planeta, mudaram muito ao longo dos últimos milhões, milhares e centenas de anos. A extinção ou florescimento de linhagens, fatos naturais da dinâmica ecológica da vida, tem dependido sempre do fato das espécies estarem ou não adaptadas a viver em novos cenários - a ideia essencial da boa e velha evolução por seleção natural, proposta por Charles Darwin em meados do século XIX e que continua atual. Hoje em dia, depois do crescimento e expansão da população humana, resta pouco de todo o patrimônio biológico que tínhamos há alguns séculos, já que os fragmentos de vegetação natural perdem cada vez mais espaço para atividades antrópicas. A racionalização e aumento no volume de informações fizeram com que nos tornássemos o último tipo dominante de vida do planeta, fechando a porta à possibilidade de qualquer outro animal fizesse o mesmo avanço e viesse, quem sabe, a desafiar nossa posição privilegiada na Terra.

À medida que estendemos as explicações cientificas dentro dos domínios da biologia, nós ganhamos confiança - ou ficamos aterrorizados - pela conscientização de que nosso destino como espécie depende do nosso próprio discernimento e também do bom funcionamento de inúmeros ecossistemas, e não dos caprichos de alguma entidade sobrenatural (WILSON, 1997). À medida que pensamos com humildade sobre o nosso lugar na história da vida e à medida que refletimos sobre a nossa origem biológica, começamos a perceber que os nossos antepassados ultrapassam os limites familiares ou humanos. Compartilhamos ancestrais em comum com toda e qualquer outra forma de vida, extinta ou vivente. Afinal, biologicamente falando, somos apenas mais uma entre milhões de ramificações na árvore da vida.

Nós, brasileiros, somos detentores da fauna e da flora mais ricas de toda a América do Sul e uma das mais majestosas biodiversidades de todo o mundo. Mas como estamos agindo em relação a isso? A divulgação de informações equivocadas ou incompletas ainda encontra solo fértil em nossa sociedade, que continua a ser iludida por ideias e estereótipos que visam, na maioria das vezes, unicamente estimular o consumo. Nunca fomos tão livres social e 
politicamente; ao mesmo tempo, porém, nunca fomos tão submissos ao consumismo e tão passivos em relação à qualidade das informações que nos são apresentadas. Vivemos em uma sociedade que, por um lado, usufrui de avanços tecnológicos surpreendentes, mas, por outro, está mergulhada em uma futilidade angustiante (LIPOVETSKY, 2006).

Apenas uma sociedade esclarecida e consciente da riqueza biológica de seu país é capaz de identificar um discurso progressista meramente mercantilista imbuída em uma prática que polui nossos mares e rios, que devasta nossos biomas e que extirpa do território nacional variedades genéticas únicas. Estamos aprendendo que não há como pensar em desenvolver um país sem investimentos em Educação (básica e universitária) e em estratégias para conservar suas riquezas, elaborando planos racionais para sustentá-la. Devemos, portanto, tomar consciência de nosso papel no gerenciamento da biodiversidade e de reflexões e ações que garantam que o futuro ainda espelhe essa grandeza de formas de vida. Que entre outras mil, que ainda seja o Brasil a nosso pátria amada e idolatrada. Mas que seja, sobretudo, diversificada e conservada.

\section{Referências citadas}

BARRET, G. W. 2001. Closing the ecological cycle: The emergence of integrative science. Ecosystem Health, 7 (2), 79 - 84.

Bíblia sagrada, 1965. 21ª edição. SP, Edições Paulina, p. 695-6.

COHEN, O. 2013. O segredo das formigas. Revista Super Interessante, ed. 318/maio, disponível em: http://super.abril.com.br/mundo-animal/segredo-formigas-748357.shtml

DIEGUEZ, F. \& PAPAROUNIS, D. 1993. Formigas saúvas: gênios trabalhando. Revista Super Interessante, ed. 067/abril, disponível em: http://super.abril.com.br/mundoanimal/formigas-sauvas-genios-trabalhando-440721.shtml

FREIRE, P. 1987. Pedagogia do oprimido. $17^{\mathrm{a}}$ ed. Rio de Janeiro, Paz e Terra.

GULLAN, P, J. \& CRANSTON, P. J. 2012. Os insetos, um resumo de entomologia, 4.ed. SP, Editora Roca.

LIPOVETSKY, G. 2007. A sociedade da decepção. São Paulo: Manole.

LOPES, B. 2007. Coldscapes. National Geographic Magazine, ed. 12/dezembro, disponível em: http://ngm.nationalgeographic.com/2007/12/permafrost/barry-lopez-text

LUGO, A. E., FARNWORTH, E. G., POOLE, D., JEREZ, P. \& KAUFMAN, G. 1973. The impact of the leaf-cutter and Atta colombica on the energy flow of a tropical wet forest. Ecology 54, 1292-301. 
KATES, R. W., W. C. CLARK, R. CORELL, J. M. HALL, C. 2001. Sustainability science. Science, Vol. 292, p. 641-642.

ODUM, E. P. \& BARRET, G.W. 2007. Fundamentos de Ecologia. São Paulo: Thomson Learning, $612 \mathrm{p}$.

OLIVEIRA, M. T. C. 1990. A dura vida das formigas. Revista Super Interessante, ed. 035/agosto, disponível em: http://super.abril.com.br/mundo-animal/dura-vida-formigas439565.shtml

ROSA, J. G. 2001. São Marcos (p. 282) / A hora e a vez de Augusto Matraga (p. 401-2) In: Sagarana. $71^{a}$ edição, Rio de Janeiro: Nova Fronteira.

SCHULTS, K. 2014. Formigas podem contribuir para desacelerar efeito estufa. Revista Scientific American Brasil, ed. 035/agosto, disponível em: http://www2.uol.com.br/sciam/noticias/formigas_podem_contribuir_para_desacelerar_e feito_estufa.html

TORRES, C. A. 1997. Pedagogia da luta: da pedagogia do oprimido à escola pública popular. Campinas: Papirus.

WEISDORF, J. L. 2005. From Foraging To Farming: Explaining The Neolithic Revolution. Journal of Economic Surveys, 19: 561-586. doi: 10.1111/j.0950-0804.2005.00259.x.

WILSON, E. O. 1997. Naturalista. Ed. Novo Fronteira - Tradução: Leonardo Fróes, 368 p. 1999. Consilience: The Unity of Knowledge. Tradução Ivo Korytovski - Rio de Janeiro : Campus.

2008. Criação: como salvar a vida na Terra. Tradução Isa Mara Lando. São Paulo : Companhia das Letras

2013. A conquista social da Terra - Tradução Ivo Korytovski - $1^{\text {a }}$ ed. - São Paulo : Companhia das Letras. 